\title{
Asthma and Tobacco: Not to Be Shared With Family and Friends!
}

In 1850, John Webster MD, a Fellow of the Royal College of Physicians, wrote in the London Journal of Medicine regarding the adverse health effects of tobacco smoking:

\footnotetext{
But although intemperance in spirituous liquors be almost unknown in certain ranks, a vice appears to have taken its place, which I think as great an abomination, and equally destructive to health, namely, tobacco-smoking, especially among the younger portion of the male population. ${ }^{1}$
}

Over 160 years later, the paper in this issue of RESPIRATORY CARE by Mak et $\mathrm{al}^{2}$ adds to the evidence that exposure to tobacco smoke leads to adverse health effects. This study of a large sample of primarily teenagers in Hong Kong examined several variables, looking for additive associations of asthma symptoms. The authors found an increased probability of asthma symptoms occurring when exposed to tobacco smoke from heavy smokers, and having a parent and a best friend who smoke greatly place adolescents at risk. There are limitations to the generalizability of the results, mainly exposure to other air pollutants such as ozone $\left(\mathrm{O}_{3}\right)$, particulate dust, and vapors that were not considered for this dense urban environment. Regardless, this study does point to the value for tobacco and air quality regulation.

Currently, most states in the U.S.A. have bans on smoking in public areas. The most recent federal law The Family Smoking Prevention and Tobacco Control Act (Public Law 111-31, HR 1256), enacted June 22, 2009, is geared primarily to the protection of children and adolescents. This law gives the FDA the authority to regulate tobacco, specifically the manufacture, labeling, advertising, distribution, and sales. Oversight and enforcement powers are also delegated to the FDA. You may recall in 2010 the request for citizen input on cigarette packaging concerning images showing the very graphic and detrimental health effects of smoking tobacco. Nine graphic warnings were proposed in June 2011, and were to cover the entire top half of cigarette packs (front and back), and include the telephone number for a stop-smoking hotline, 800-QUITNOW. The images were to be on all cigarette packages by January 2013, but, unfortunately, Lorillard corporation and other cigarette makers filed a lawsuit arguing that the warnings relegate the companies' brands to the bottom half of the cigarette packaging, which infringes on their right to free speech. This led to an injunction in November 2011, which temporarily blocked the packaging requirements. In February 2012, a United States district judge ruled that the mandate to put images on cigarette packaging violated the free speech amendment to the Constitution. The FDA appealed, and in April a federal appeals court weighed the constitutionality of requiring large graphic photographs. Now the tobacco companies argue that the warnings go beyond truthful information into anti-smoking advocacy. They contend that the photographs of dead and diseased smokers are not factual. No doubt many of us know the real truth in this matter. Just ask our chronic lung patients who are choking to death from active, passive, and third hand smoke. Fortunately, in July a federal appeals court upheld the order that tobacco companies are to place corrective advertising about the danger of smoking.

See the Original Study on Page 1398

As noted by Mak et al, ${ }^{2}$ the prevalence of asthma among adolescents in Hong Kong is higher than those living in mainland China or in the West, ${ }^{3}$ but decreasing, as reported in recent years. ${ }^{4}$ The latest statistics for asthma in the United States are alarming and show just the opposite. Currently, the asthma prevalence is $8.2 \%$ for adults and $9.6 \%$ for children (defined as $0-17$ years of age). ${ }^{5}$ Of these children seeking care for their asthma, 20\% go to the emergency department, and 50\% of them do not have an asthma action plan. ${ }^{6}$ Mak and his co-authors give those of us in the United States involved in chronic asthma disease management and tobacco addiction and control reason to believe that efforts can pay off, even though we may not see any improvement for some time. Public health programs; local, state, and national clean air laws; and regulation of tobacco by the FDA are good for our country, but it still comes down to the respiratory therapist working one-on-one with our most vulnerable populations to make lasting changes.

Lynda Thomas Goodfellow EdD RRT AE-C FAARC Division of Respiratory Therapy Byrdine F Lewis School of Nursing and Health Professions Georgia State University Atlanta, Georgia 


\section{Asthma and Tobacco: Not to Be Shared With Family and Friends!}

\section{REFERENCES}

1. Webster J. On the health of London during the six months terminating September 28, 1850. London J Med 1850; number XXIV.

2. Mak KK, Ho RCM, Day JR. The associations of asthma symptoms with active and passive smoking in Hong Kong adolescents. Respir Care 2012;57(9):1398-1404.

3. Wang HY, Wong GW, Chen YZ, Ferguson AC, Greene JM, Ma Y, et al. Prevalence of asthma among Chines adolescents living in Canada and China. CMAJ 2008;179(11):1133-1142.

4. Wong GW, Leuong TF, Ko FW, Lee KK, Lam P, Hui DS, et al.

The author has disclosed no conflicts of interest.

Correspondence: Lynda Thomas Goodfellow EdD RRT AE-C FAARC, Division of Respiratory Therapy, Byrdine F Lewis School of Nursing and
Declining asthma prevalence in Hong Kong Chinese schoolchildren. Clin Exp Allergy 2004;34(10):1550-1555.

5. Akinbami LJ, Moorman JE, Lui X; Office of Analysis and Epidemiology; National Center for Health Statistics. Asthma prevalence, health care use, and mortality: United States, 2005-2009. National Health Statistics Report No. 32 January 12, 2011. http://www.cdc. gov/nchs/data/nhsr/nhsr032.pdf. Accessed June 25, 2012.

6. Centers for Disease Control and Prevention. Asthma's impact on the nation: data from the CDC national asthma control program. http:// www.cdc.gov/asthma/impacts_nation/AsthmaFactSheet.pdf. Accessed June 25, 2012.

Health Professions, Georgia State University, PO Box 3995, Atlanta GA 30302. E-mail: LTGoodfellow@gsu.edu.

DOI: $10.4187 /$ respcare. 02056 